\title{
Epothilone A
}

National Cancer Institute

\section{Source}

National Cancer Institute. Epothilone A. NCI Thesaurus. Code C1622.

An extract from the myxobacteria Sorang ium cellulosum that promotes tubulin

polymerization and microtubule stabilization, thereby inhibiting mitosis. Epothilone A appears to be less potent than Epothilone B. $(\mathrm{NCl})$ 